\title{
COMPARISON OF THERMAL TRANSFER AND INKJET PRINTING OF UHF RFID TAG ANTENNAS ON PAPER SUBSTRATES
}

\author{
Juraj Gigac, Mária Fišerová, Svetozár Hegy \\ Pulp and Paper Research Institute Bratislava \\ Slovak Republic \\ (Received October 2020)
}

\begin{abstract}
UHF RFID printed antennas on conventional and experimentally coated papers by thermal transfer and inkjet technique were not conductive due to high surface roughness. Reducing the surface roughness of paper and hence the electrical resistance of the antennas printed by thermal transfer and inkjet printing was achieved by coating and subsequent calendering process. Papers for thermal transfer and inkjet printed of aluminum and silver antennas were prepared by coating with top functional coating, whose main component was pigment - precipitated calcium carbonate with addition of polyvinyl alcohol, cationic polymer PDADMAC and glyoxal. The desired quality of inkjet-printed silver antennas was achieved by using coated paper with a polyvinyl alcohol barrier layer and a top functional hydrophilic layer. Silver nanoparticles of inkjet ink require a sintering process to obtain a conductive printed trace. The microstructure and thickness of antennas printed by thermal transfer and inkjet technique were compared. Thermal transfer printing created a more homogeneous antenna with greater sharpness of drawing compared to inkjet printing.
\end{abstract}

KEYWORDS: Paper, coating, calendering, thermal transfer printing, inkjet printing, RFID antenna, electrical resistance.

\section{INTRODUCTION}

RFID is a wireless identification technology to automatically identify and track physical objects or people by using radio frequency waves. This technology has several benefits over the conventional ways of identification, such as greater read range, faster data transfer, the ability to insert RFID tags into objects, the line-of-sight is not neccessary, and the ability to read a huge number of tags simultaneously (Want 2006). Passive UHF (Ultra High Frequency) RFID technology is beneficial in embedded applications as passive tags require minimal maintenance 
because no battery replacement is required. The read ranges of passive UHF RFID systems are larger compared to other RFID frequencies (Dobkin 2013).

Printed antennas are usually applied to different plastic foils (Chin et al. 2012, Janeczek 2010, Betancourt and Castan 2013, Arazna et al. 2017). Recently, the popularity of RFID has increased significantly, particularly in relation to printing of antennas on paper substrates (Melampi et al. 2007, Tentzeris et al. 2007, Yang et al. 2007, Rida et al. 2009, Lakafosis et al. 2010, Jingtian et al. 2011, Zichner and Bauman 2011, Öhlund and Andersson 2012, Bollström and Toivakka 2013, Merilampi et al. 2014, He et al. 2016, Gigac et al. 2020). Modifications of paper substrates and printing processes are required in order to obtain working electronic devices. Coating and calendering processes can be used to modify the paper surface (Gigac et al. 2013, Stankovská et al. 2014). The paper surface is usually smoothed with a dispersion coating consisting of mineral pigments and organic binders. The smoothness of paper surface depends on composition of coatings, the number of coating layers and the final surface treatment. The surface properties of papers can be adjusted at the same time to achieve the desired functional properties, such as surface energy for print receptivity, water, oil and grease resistance, low vapor and gas permeability, and flame retardation. A number of techniques are available for printing electronics. These include well known and widely used methods inkjet and screen printing. They use an ink containing conductive particles or flakes typically metallic, which then requires sintering to achieve the maximum available conductivity. Thermal transfer printing use metal ribbons for printed electronics without the need of sintering step, which is esential in inkjet printing. The thickness of the metal in thermal transfer printing is relatively small (approximately $300 \mathrm{~nm}$ ) compared to the metal thickness printed with the inkjet, which may be more than $1 \mu \mathrm{m}$ (Kgwadi et al. 2014, Whyte et al. 2010).

Inkjet printing is a digital and non-contact technique that is almost free of chemical waste and doesn't require special facilities for its use. The possibility of using well known substrates like paper or polymer foils enables flexible, cheap and disposable device. It is ideal for fast prototyping and high throughput, low cost and improved environment-friendliness (Albrecht et al. 2016). The inks used for electronic printing are typically made of copper and/or silver nanoparticles due to their high electrical conductivity in an organic solvent and polymer coating (Dearden et al. 2004, Perelaer et al. 2006, Park et al. 2007). The polymer coating of the metal nanoparticles serves as stabilizer the dispersed particles in the ink to prevent them from coalescing, merging into larger aggregates, and clogging the print head nozzles in the inkjet printer. Printing of the conductive elements with metallic nanoparticle inks must be followed by an additional sintering step, usually achieved by heating to elevated temperature. Without sintering the printed trace of the metallic particles, nano-silver ink acts as an insulator in its as dried state. (Greer and Street 2007). The silver nanoparticle-based ink for printing of electronics has been developed, having a built-in sintering mechanism, which is triggered during drying of the printed pattern (Gouchko et al. 2011).

One digital printing technology that has not received much attention in the printed electronics arena is thermal transfer printing. Thermal transfer printing is a digital printing method in which material is applied to paper (or some other material) by melting a coating of ribbon so that it stays glued to the material on which the print is applied. It contrasts with direct thermal printing, where no ribbon is present in the process. Thermal transfer is a popular printing process particularly used for the printing of identification labels. It is the most widely used printing process in the world for the printing of high-quality barcodes. Thermal transfer printing contrasts with direct thermal printing where no tape is present in the process but a heatsensitive substrate. Thermal transfer is preferable to direct thermal printing on heat-sensitive surfaces or when a longer life of the printed materials is desired. The thermal transfer ribbon 
consists of a heat-resistant coating, a polyethylene terephthalate carrier film, a release layer, a vacuum metallized continuous layer and a thermoplastic tie layer. The carrier is a heat-resistant polyester film that has high tensile strength and, when thermally stabilized, transfers heat from the tips of the printer without excessive expansion. The release layer is prepared from waxy solids that are thermally softened during printing and which have a low cohesive strength. Because it is soft, it is disrupted by most subsequent operations, including printing or gluing. The metallized layer is a continuous conductor deposited on the release layer by vacuum deposition. The final layer is a thermoplastic adhesive that binds the metallized layer to the substrate when heated to form an image.

The aim of the work was to compare the influence of paper substrates, plastic foils, thermal transfer and inkjet printing as well as the design of UHF RFID antennas on their electrical resistance.

\section{MATERIAL AND METHODS}

\section{Printing substrates}

(1) Paper TTP - Thermal Transfer Paper Ultra 80 (Jujo Thermal), was calendered by two passes in a laboratory calender Kleinewefers at a linear load in the nip of $260 \mathrm{kN} \cdot \mathrm{m}^{-1}$ and a metal roller temperature of $80^{\circ} \mathrm{C}$.

(2) Paper CFC-Coated Folding Carton MB PRO FBB Bright, 185 gsm (Grafobal, Skalica, SK) was calendered by two passes in a laboratory calender Kleinewefers at a linear load in the nip of $260 \mathrm{kN} \cdot \mathrm{m}^{-1}$ and a metal roller temperature of $80^{\circ} \mathrm{C}$.

(3) Paper EXP-PAP_1 - Base paper experimentally produced on pilot plant paper machine in Pulp and Paper Research Institute (Bratislava, SK) and sized into mass with $0.3 \%$ AKD (alkyl ketene dimer) was coated with a mixture of precipitated calcium carbonate pigment (100\%), 30\% polyvinyl alcohol (PVOH), 2.5\% cationic polymer SMAI 1000 (styrene maleic anhydride imide). The coated paper was finally calendered by two passes in a laboratory calender Kleinewefers at a linear load in the nip of $260 \mathrm{kN} \cdot \mathrm{m}^{-1}$ and a metal roller temperature of $80^{\circ} \mathrm{C}$.

(4) Paper EXP-PAP_2 - Base paper-Balance Pure Offset from 100\% recycled fibres was coated with a mixture of precipitated calcium carbonate pigment (100\%), 20\% PVOH, 2.5\% cationic polymer SMAI 1000. The coated paper was finally calendered by two passes in a laboratory calender Kleinewefers at a linear load in the nip of $260 \mathrm{kN} \cdot \mathrm{m}^{-1}$ and a metal roller temperature of $80^{\circ} \mathrm{C}$.

(5) Paper EXP-PAP_3 - Base paper experimentally produced on pilot plant paper machine in Pulp and Paper Research Institute (Bratislava, SK) and sized into mass with $0.3 \%$ AKD (alkyl ketene dimer) was coated with a mixture of precipitated calcium carbonate pigment (100\%), 30\% PVOH, 2.5\% cationic polymer PDADMAC (poly diallyldimethyl-ammonium chloride). The coated paper finally calendered by two passes in a laboratory calender Kleinewefers at a linear load in the nip of $260 \mathrm{kN} \cdot \mathrm{m}^{-1}$ and a metal roller temperature of $80^{\circ} \mathrm{C}$.

(6) Paper EXP-PAP_4 - Base paper (Balance Pure Offset from 100\% recycled fibres) was coated with a mixture of precipitated calcium carbonate pigment (100\%), 30\% PVOH, $2.5 \%$ cationic polymer PDADMAC. The coated paper was finally calendered by two passes in a laboratory calender Kleinewefers at a linear load in the nip of $260 \mathrm{kN} \cdot \mathrm{m}^{-1}$ and a metal roller temperature of $80^{\circ} \mathrm{C}$.

(7) Barrier coated inkjet paper EXP-IJP_BC-Base paper was coated with $\mathrm{PVOH}$ barrier coating and with top functional coating, whose basic component was an aqueous-isopropyl alcohol dispersion of a mixture of precipitated calcium carbonate pigment (100\%), 30\% PVOH, 
$2.5 \%$ cationic polymer PDADMAC. The coated paper was finally calendered by two passes in a laboratory calender Kleinewefers at a linear load in the nip of $260 \mathrm{kN} \cdot \mathrm{m}^{-1}$ and a metal roller temperature of $80^{\circ} \mathrm{C}$.

(8) PET (polyethylene terephthalate) foil NOVELE obtained from NovaCentrix was used as a reference substrate for printing UHF RFID antennas.

(9) PET labels from Acoding Company, SK.

\section{Antennas design}

UHF RFID antenna 1 - Type DogBone i, product of the Smartrac division of the company Avery Dennison, compatible with chip NXP UCODE G2iL / iM or Impinj Monza 5. UHF RFID antenna 2 - Type undefined. UHF RFID antenna 3 - Type AD-227m5 from the company Avery Dennison, compatible with chip Impinj Monza 5 (Fig. 1).

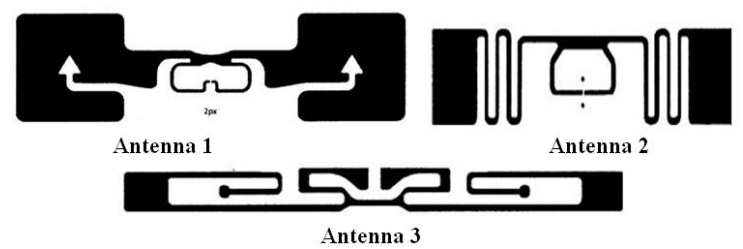

Fig. 1: Design of UHF RFID antennas.

\section{Methods}

Top functional coating of base papers for the preparation of (barrier-free) thermal transfer papers and inkjet papers was realized by laboratory knife coater (DOW Chemicals). Barrier coating of the base papers for the preparation of the barrier inkjet paper was realized by bar coating. Calendering of papers was performed by two passes in a laboratory calender Kleinewefers at a linear load in the nip of $260 \mathrm{kN} \cdot \mathrm{m}^{-1}$ and a metal roller temperature of $80^{\circ} \mathrm{C}$. Thermal transfer printing with conductive aluminum thermal transfer ribbon Metallograph ${ }^{\circledR}$ from companies SPF-Inc. and IIMAK in industrial printer SATO CL4NX with output of 3000-25000 antennas per hour (aluminum foil thickness $260 \mathrm{~nm}$, thermal print head $305 \mathrm{dpi}$, substrate thickness up to $280 \mu \mathrm{m})$. Inkjet printing with conductive AgNPs ink Metalon JS-B25P from company NovaCentrix in the piezoelectric desktop printer EPSON Stylus 88+ (drop volume $3 \mu \mathrm{L}$, substrate thickness up to $110 \mu \mathrm{m}$ ). Sintering (curing) of inkjet-printed antennas was carried out at downforce of $75 \mathrm{kPa}$ of the hot flat press heated to $130^{\circ} \mathrm{C}$ for 15 seconds.

Electrical resistance of the antennas was measured corner to corner using a multimeter UNIT-T, Model UT70B. The microstructure and thickness of the aluminum and silver antennas were determined by scanning electron microscopy (SEM) using a JEOL JSM 6610 microscope equipped with an EDS detector X-Max $50 \mathrm{~mm}^{2}$ (Oxford Instruments Ltd.). Antenna samples were cut, ultrasonically cleaned and observed in a microscope at various magnifications. The surface of the samples was subjected to EDX analysis in an electron microscope at magnification 250x. Subsequently, all samples were glued vertically on the holder, and encapsuled into conductive potting mass. Samples were prepared metallographically - sanded and polished to the desired shape and surface. Subsequently they were rinsed in isopropyl alcohol, ultrasonically cleaned and thoroughly dried.

The distance between the ends of the UHF RFID antennas (in a place where the chip connects to the antenna) was measured at 50x magnification using a Leitz Wezler OP light microscope (Germany) and a Nicon Coolpix 4500 CCD camera (Japan). 


\section{RESULTS AND DISCUSSION}

Paper has a rougher surface compared to a plastic foil, which is currently most frequently used as a substrate for printing UHF RFID antennas. Irregular surfaces and structural properties of conventional papers require higher ink consumption, which is achieved by conventional printing technique such as screen printing. In order to improve printability, research of label and packaging paper production technology is aimed at improving surface smoothness and absorption properties of paper. Thermal transfer and inkjet printing of antennas on uncalendered and calendered papers with surface roughness over $6 \%$, expressed by optical variability of surface, provided only non-conductive antennas. The optical variability of paper surface was evaluated by the photoclinometric method (Kasajová and Gigac 2013, Gigac et al. 2013, 2014).

\section{Electrical resistance of antennas}

Fig. 2 compares the electrical resistance of three antenna designs (Fig. 1) printed by thermal transfer printing on calendered commercial and experimentally coated papers with antennas printed on PET label.

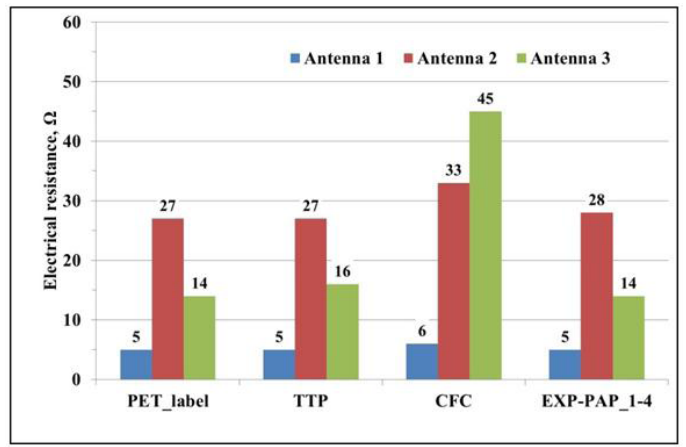

Fig. 2: Comparison of electrical resistance of antennas printed by thermal transfer printing on calendered commercial papers and calendered experimentally coated papers with antennas printed on PET label.

The design of antennas has a significant effect on their electrical resistance, which depends on the length of the antenna and is strongly influenced by the geometric dimensions of its narrowest part. Meander antenna 2 is the longest, so it has a higher electrical resistance compared to antennas 1 and 3.

The aim of paper coating and calendering was to improve its surface smoothness and the quality of UHF RFID antennas printed by the thermal transfer and inkjet printing. The electrical resistances of antennas printed with conductive Al ribbon by thermal transfer printing on calendered commercial paper (TTP) and calendered experimentally coated papers (EXP-PAP_1-4) were comparable to those of printed antennas on PET label.

The electrical resistances of antenna 2 and antenna 3 printed on calendered commercial paper (CFC) were about $6 \Omega$, respectively about $31 \Omega$ higher than the resistances of the antennas printed on the PET label. The higher electrical resistance of the antennas printed on CFC paper was due to the higher surface roughness (6.2\%) compared to other papers (5.2- 5.8\%) and PET labels. Surface roughness was evaluated by photoclinometric method as optical variability of surface (Gigac et al. 2020). 
Calendered experimentally coated papers (EXP-PAP_1-4) prepared for thermal transfer printing of antennas were also printed by inkjet printing. Electrical resistances of antennas 1, 2 and 3 (Fig. 1) printed by both printing techniques are shown in Figs. 3-5. The electrical resistances of the UHF RFID antennas 1, 2, 3 printed by thermotransfer printing on all tested papers were lower compared to the inkjet printed antennas. The electrical resistance of antennas was significantly influenced by the antenna design, regardless of printing technique. Calendered experimentally coated papers EXP-PAP_3 and EXP-PAP_4 are suitable for printing antennas with both printing techniques.

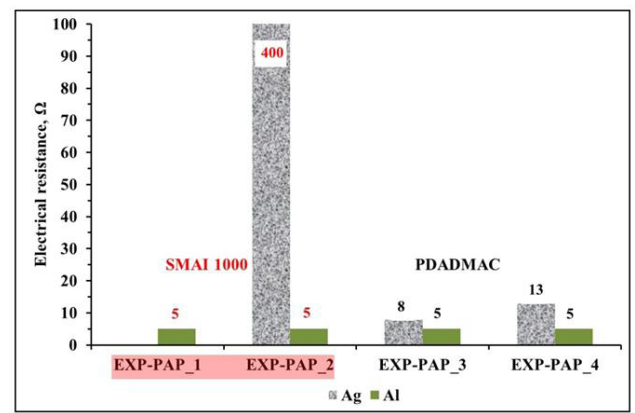

Fig. 3: Effect of cationic polymer in coatings of calendered experimentally coated papers on electrical resistance of Antenna 1 printed by thermal transfer $(A l)$ and inkjet $(A g)$ printing (in coating of papers EXP-PAP_1 and EXP-PAP_2 was SMAI 1000 and of papers EXP-PAP_3 and EXP-PAP_4 was $P D A D M A C)$.

The antenna 1 printed by inkjet printing on these papers had electrical resistances 8 and $13 \Omega$ (Fig. 3), the antenna 2 had electrical resistances 68 and $73 \Omega$ (Fig. 4), and the antenna 3 (Fig. 5) had electrical resistances 24 and $25 \Omega$. Inkjet-printed antennas 1, 2, 3 on papers EXPPAP_1 and EXP-PAP_2 were nonfunctional as they were nonconductive with high electrical resistance. A high electrical resistance of up to $400 \Omega$ was measured on antenna 1 (Fig. 3). The only difference between the calendered experimentally coated papers was the type of cationic polymer used in preparation of the coating compositions and the type of base paper. The effect of the paper substrate on electrical resistance of the printed antennas on calendered experimentally coated papers was not detected.

We assume that the application of the cationic polymer SMAI 1000 in coatings of papers EXP-PAP_1 and EXP-PAP_2 caused the nonfunctioning of the inkjet printed antennas. A more suitable cationic polymer PDADMAC was used in the coatings of papers EXP-PAP_3 and EXP-PAP_4. For sintering the silver particles must be very close - touching. From a colloid perspective that is best if they are not flocculated. Perhaps the SMAI is causing flocculation with the silver particles being separated so not close enough to sinter. With PDADMAC in the mix they are sintering. 


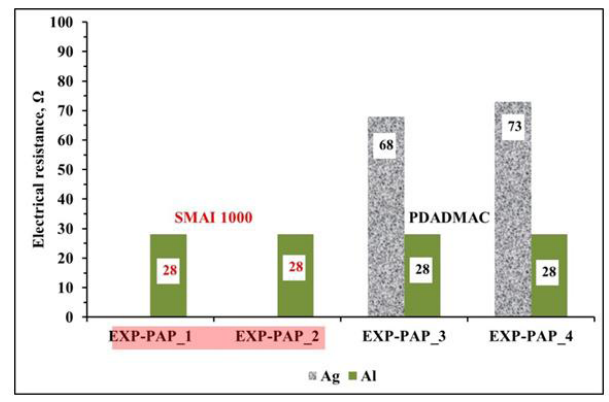

Fig. 4: Effect of cationic polymer in coatings of calendered experimentally coated papers on electrical resistance of Antenna 2 printed by thermal transfer (Al) and inkjet (Ag) printing (in coating of papers EXP-PAP_1 and EXPPAP_2 was SMAI 1000 and of papers EXPPAP_3 and EXP-PAP_4 was PDADMAC).

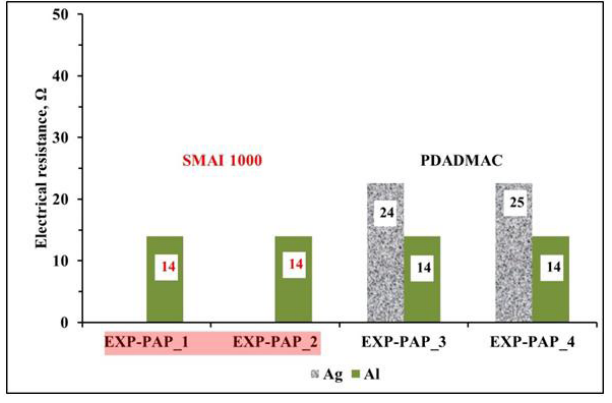

Fig. 5: Effect of cationic polymer in coatings of calendered experimentally coated papers on electrical resistance of Antenna 3 printed by thermal transfer (Al) and inkjet (Ag) printing (in coating of papers EXP-PAP_1 and EXPPAP_2 was SMAI 1000 and of papers EXP$P A P \_3$ and EXP-PAP_4 was PDADMAC).

To produce a UHF RFID tag with a large reading range, high quality printed antenna with the lowest electrical resistance is required. Lower electrical resistance of aluminum antennas prepared by thermal transfer printing compared to silver antennas printed by inkjet printing on calendered experimentally coated papers EXP-PAP_3 and EXP-PAP_4 is in good agreement with the results of electrical resistances of antennas printed by thermal transfer and inkjet printing on plastic substrate THERMLfilm (Kgwardi et al. 2016). In this work, aluminum UHF RFID tags had lower electrical resistance, and their reading range was greater than of silver ones.

The desired quality of silver antennas was achieved using calendered experimentally paper with a top functional coating on a barrier coating of the base paper. The top functional coating was composed of a mixture of precipitated calcium carbonate (100\%), PVOH (30\%), cationic polymer (2.5\%) and glyoxal (2\%). Polyvinyl alcohol was used for the barrier coating.

Due to the presence of a barrier layer under the top functional coating in the calendered experimentally coated EXP-IJP_BC paper, the electrical resistance of antennas 1, 2 and 3 was reduced to the level of aluminum and silver antennas on the plastic substrate PET Novele. (Tab. 1).

Tab. 1: Comparison of electrical resistances of inkjet printed antennas on calendered experimentally papers and plastic substrate.

\begin{tabular}{|l|l|c|c|c|}
\hline \multicolumn{1}{|c|}{ Paper } & \multicolumn{1}{|c|}{ Description } & $\begin{array}{c}\text { Antenna 1 } \\
(\Omega)\end{array}$ & $\begin{array}{c}\text { Antenna 2 } \\
(\Omega)\end{array}$ & $\begin{array}{c}\text { Antenna 3 } \\
(\Omega)\end{array}$ \\
\hline EXP-PAP_3 & Barrier-free with calendered top coating & 8 & 68 & 24 \\
\hline EXP-PAP_4 & Barrier-free with calendered top coating & 13 & 73 & 25 \\
\hline EXP-IJP_BC & Barrier with calendered - top coating & $2.9-4.3$ & $24-42$ & $10.4-11.3$ \\
\hline PET foil & NOVELE - Ag antenna & $3.9-4.1$ & $21-34$ & $7.6-10.2$ \\
\hline PET foil & $\begin{array}{l}\text { NOVELE - Al antenna } \\
\text { (Termal tranfer printing) }\end{array}$ & 5 & 28 & 14 \\
\hline
\end{tabular}




\section{Characterization of antennas}

Chemically etched aluminum antennas on plastic UHF RFID tags are shown in cross section using SEM microscopy in Fig. 6. The average thickness of the antennas was $10.12 \mu \mathrm{m}$ (a), $16.48 \mu \mathrm{m}$ (b) and $12.80 \mu \mathrm{m}$ (c).
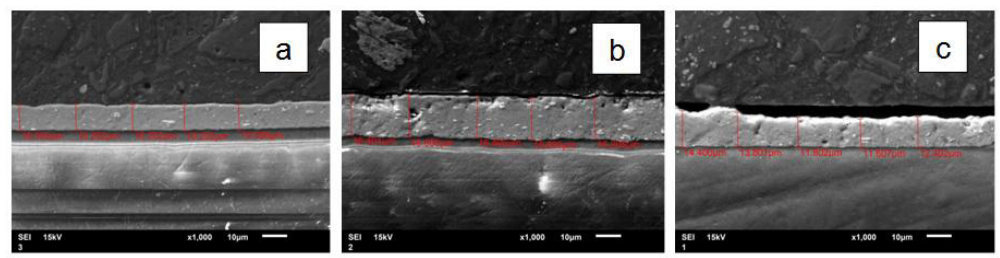

Fig. 6: SEM microstructure of chemically etched aluminum antennas on PET foil in cross section with the aluminum layer shown.

The thickness of the aluminum antenna printed by thermal transfer technique on PET foil (Fig. 7) was $260 \mathrm{~nm}$, as well as on paper EXP-PAP_3 (Fig. 8), as it is given by the thickness of the aluminum layer on the Metallograph ${ }^{\circledR}$ ribbon.

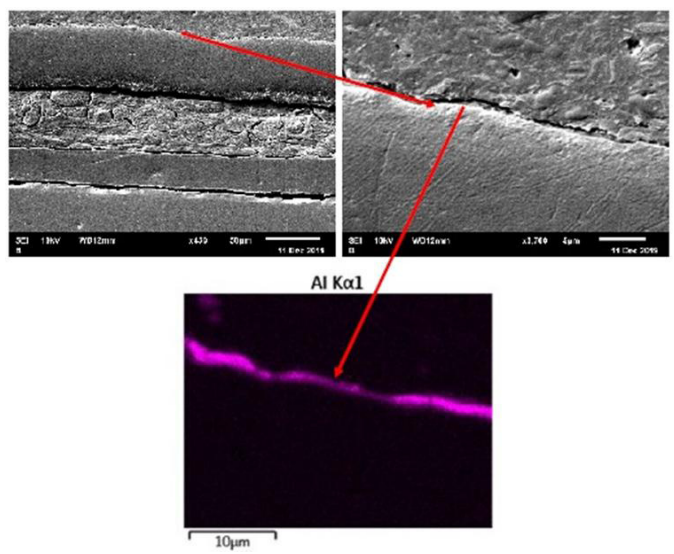

Fig. 7: SEM microstructure of an aluminum antenna printed by thermal transfer technique on PET foil in cross section with the aluminum layer shown by EDS mapping.

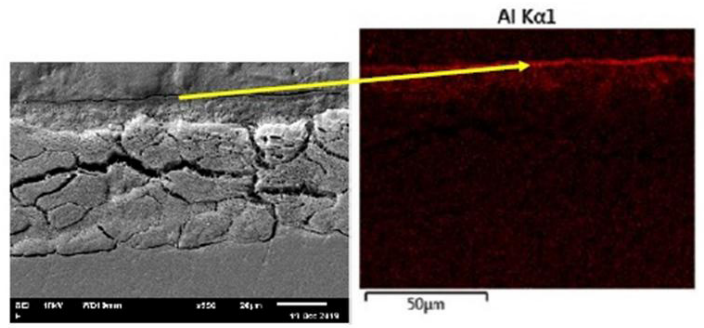

Fig. 8: SEM microstructure of an aluminum antenna printed by thermal transfer technique on paper EXP-PAP_3 in cross section with the aluminum layer shown by EDS mapping. 
The average thickness of the silver antenna fabricated with inkjet printing technique on PET foil (Fig. 9) was $1.29-1.69 \mu \mathrm{m}$.

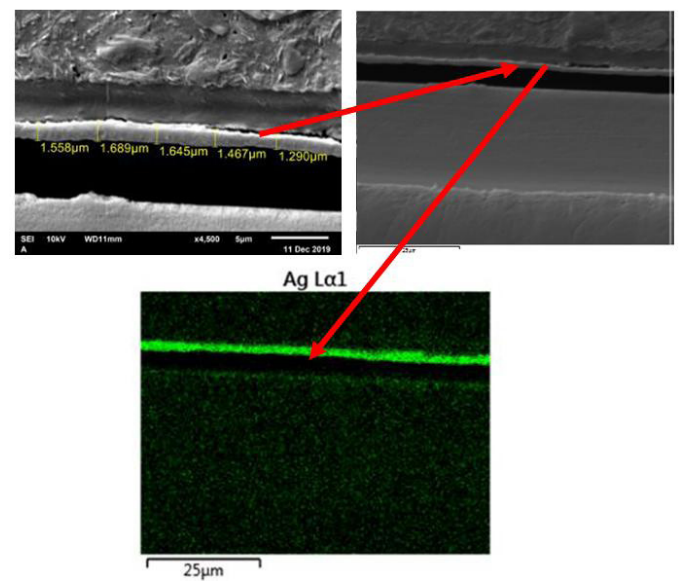

Fig. 9: SEM microstructure of a silver antenna printed by inkjet technique on PET foil in cross section with the silver layer shown by EDS mapping.

A comparison of thickness and material of the conductive film of the UHF RFID antenna according to the technique used is shown in Tab. 2. Compared to conventional printing techniques such as inkjet, screen, flexo and gravure printing, thermal transfer printing uses 130 times cheaper aluminum compared to silver and eliminates the sintering process of silver nanoparticles. The advantage of thermal transfer printing is also low aluminum consumption, as it is applied in thickness of $260 \mathrm{~nm}$. The advantage of a greater thickness of the $\mathrm{Ag}$ and $\mathrm{Cu}$ conductive film in conventional printing methods and hot stamping is the good printability of substrates even with a rougher surface.

Tab. 2: Thickness and material of conductive film according to an antenna preparation technique.

\begin{tabular}{|l|c|c|}
\hline \multicolumn{1}{|c|}{ Technique } & Thickeness of conductive film $(\boldsymbol{\mu m})$ & Antenna material \\
\hline Screen printing & $4-16$ & $\mathrm{Ag}$ \\
\hline Flexo printing & $1-2$ & $\mathrm{Ag}$ \\
\hline Gravure & $0.5-2.0$ & $\mathrm{Ag}$ \\
\hline Inkjet printing & $0.3-1.5$ & $\mathrm{Ag}$ \\
\hline Thermal transfer printing & 0.26 & $\mathrm{Al}$ \\
\hline Hot stamping (Taylor and Harrison 2017) & 0.34 & $\mathrm{Cu}$ \\
\hline Chemical etching & 10 and more & $\mathrm{Al}$ \\
\hline
\end{tabular}

In Tab. 2, in addition to printing techniques, there is also an etching technique which is currently used in the production of RFID tags. Aluminum antennas produced by chemical etching of the aluminum layer on a plastic foil have a thickness of $10-16 \mu \mathrm{m}$.

Details of UHF RFID antenna 1 printed by thermal transfer and inkjet printing on calendered experimentally coated paper and PET foil (Novele) were evaluated. The distance between the ends of the UHF RFID antenna at 50x magnification was measured using by light 
microscop and a CCD camera. The gap between the ends of the antennas is the place where the chip is connected. Based on the measurement results in Fig. 10 it can be stated that distance between the ends of the dipole UHF RFID antenna was by 75-105 $\mu \mathrm{m}$ shorter achieved with inkjet printing (Ag nanoparticles) than with thermal transfer printing (Al ribbon). The gap size is adjusted by changing the print template for each printer. Thermal transfer printing is more homogeneous and has a sharper drawing.

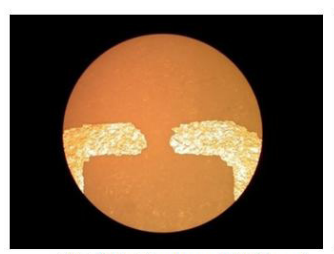

PET foil_Al antenna $1(320 \mu \mathrm{m})$

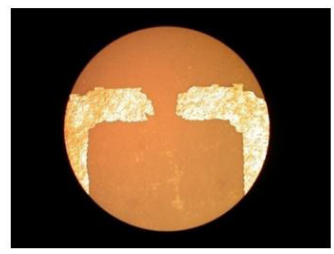

Calendered experimentally coated paper_Al antenna $1(300 \mu \mathrm{m})$

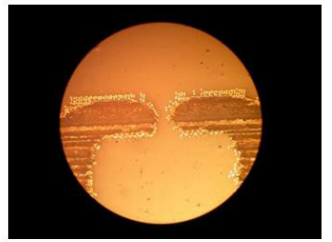

PET foil_Ag antenna $1(215 \mu \mathrm{m})$

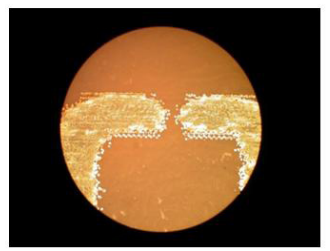

Calendered experimentally coated paper_Ag antenna $1(225 \mu \mathrm{m})$

Fig. 10: Comparison of the distance between the ends of UHF RFID antenna 1 printed by thermal transfer (Al ribbon) and inkjet (Ag nanoparticles) printing on calendered experimentally coated paper and PET foil.

In Fig. 11 are SEM images of the aluminum layer and silver layers of UHF RFID antennas printed on the surface of the papers. The surfaces of aluminum and silver antennas differ significantly. The aluminum layer (a) is continuous, with little surface damage that may be related to the surface roughness of the paper. The sintered silver nanoparticles formed a porous layer (b) which reached a maximum of $65 \%$ of the conductivity of silver. In the case of a higher surface roughness of the paper, discontinuous layers (c) of silver were formed.
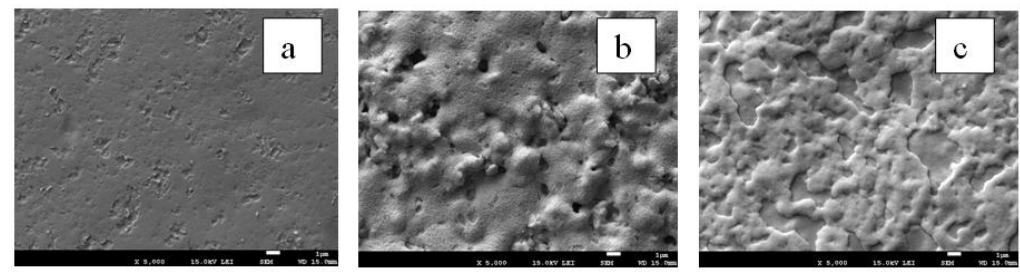

Fig. 11: SEM images of aluminum layer (a) and silver layers (b, c) of UHF RFID antennas printed on papers. 


\section{CONCLUSIONS}

Paper substrates are more suitable for printing UHF RFID antennas than plastic substrates as they are recyclable and several times cheaper. However, printed antennas on conventional papers have higher electrical resistance due to the high surface roughness than those printed on plastic substrates.

Paper surfaces have been modified by coating and calendering processes to reduce surface roughness and electrical resistance of UHF RFID antennas printed by thermal transfer and inkjet printing. Composition of the top functional coating, the main component of which was pigment precipitated calcium carbonate, and the calendering of the top coat had a positive effect on surface smoothness, electrical resistance and quality of UHF RFID antennas printed by thermal transfer and inkjet printing. Uncalendered papers and calendered papers with higher surface roughness, optical variability of surface over $6 \%$, provided only non-conductive antennas. In the case of inkjet printing, in addition to the surface roughness of the paper, the correct choice of cationic polymer for the coating colour is also important.

Electrical resistance of UHF RFID antennas printed by thermal transfer printing on calendered experimentally coated papers was lower than inkjet printed antennas. The polyvinyl alcohol-based barrier coating improved the absorption and anchoring of the inkjet ink in the top functional coating. The electrical resistance of inkjet printed silver antennas was reduced by using experimentally coated paper with barrier coating on a base paper and with a top functional coating.

The process of calendering coated folding carton (CFC), to the extent necessary to reduce the surface roughness and make a conductive UHF RFID antenna by thermal transfer or inkjet printing, was not suitable as it unacceptably reduced the stiffness of this packaging material. The required stiffness of packaging materials with conductive antennas printed on rougher surfaces can be achieved by hot stamping with a copper layer $340 \mathrm{~nm}$ thick.

The advantage of thermal transfer printing UHF RFID antennas is the use of 130 times cheaper aluminum compared to silver used in inkjet printing. In addition, aluminum consumption is low because it is applied in thickness $260 \mathrm{~nm}$, while in the case of inkjet printing, the thickness of the silver film was 1.3-1.7 $\mu \mathrm{m}$. In addition, silver nanoparticles require a sintering process to create conductive antennas with low electrical resistance. Under optimal conditions, the silver nanoparticles formed a porous layer after sintering, which reached only $30-65 \%$ of the conductivity of silver.

Antennas printed by the thermal transfer technique were more homogeneous with greater sharpness of drawing than antennas printed by the inkjet technique.

Printed antennas on paper will be used for chip installation and communication quality evaluation of prepared UHF RFID tags.

\section{ACKNOWLEDGMENT}

This work was supported by Slovak Research and Development Agency under contract No. APVV-19-0029. 


\section{REFERENCES}

1. Albrecht, A., Rivadeneyra, A., Salmerón, J., Abdellah, A., Lugli, P., 2016: Inkjet printing and photonic sintering of silver and copper oxide nanoparticles for ultra-low-cost conductive patterns. Journal of Materials Chemistry C(4): 3546-3554.

2. Arazna A., Janeczek, K., Futera, K., 2017: Mechanical and thermal reliability of conductive circuit injet printed on flexible substrates. Circuit World 43(1): 9-12.

3. Betancourt, D., Castan, J., 2013: Printed antenna on flexible low-cost PET substrate for UHF applications. Progress in Electromagnetics Research C 38: 129-140.

4. Bollström, R., Toivakka, M., 2013: Paper substrate for printed functionality. 15th Fundamental Research Symposium, Cambridge, September 2013, Pp. 945-966.

5. Dearden, A., Smith, P., Shin, D.Y., Reis, N., Derby, B., Paul O’Brien, P., 2004: A low curing temperature silver ink for use in ink-jet printing and subsequent production of conductive tracks. Macromolecular Rapid Communications 26(4): 315-318.

6. Dobkin, D., 2013: The RF in RFID: Passive UHF RFID in practice. Newnes, Elsevier, USA, second ed., 528 pp.

7. Gigac, J., Fišerová, M., Kováč, M., Stankovská M., 2020: Paper substrates for inkjet printing of UHF RFID antennas. Wood Reseaech 65(1): 25-36.

8. Gigac, J., Kasajová, M., Maholányiová, M., Stankovská, M., Letko, M., 2013: Prediction of surface structure of coated paper and of ink setting time by infrared spectroscopy. Nordic Pulp Paper Research Journal 28(2): 274-281.

9. Gigac, J., Kasajová, M., Stankovská, M., 2014: The influence of paper surface energy on multicolor offset print mottling. Tappi Journal 13(2): 55-64.

10. Greer, J.R., Street, R.A., 2007: Thermal cure effects on electrical performance of nanoparticle silver inks. Acta Materialia 55(18): 6345-6349.

11. Grouchko, M. Kamyshny, A., Mihailescu, C.F., Anghel, D.F., Magdassi, S., 2011: Conductive inks with a „built-in“ mechanism that enables sintering at room temperature. ACS Nano 5(4): 3354-3359.

12. He, H., Sydänheimo, L., Virkki, J., Ukkonen, L., 2016: Experimental study on inkjetprinted passive UHF RFID tags on versatile paper-based substrates. International Journal of Antennas and Propagation, ID 9265159, 8 pp.

13. Chin, K.C., Tsai, C.H., Chang, L.C., Wei, C.L., Chen, W.T., Chen, C.S., Lai, S.J., 2012: Design of flexible RFID tag and rectifier circuit using low cost screen printing process. http://magazines007.com/pdf/RFIDdesign.pdf.

14. Janeczek, K., 2010: Performance of RFID tag antennas printed on flexible substrates. In: XII International PhD Workshop, Wisla, Poland, Pp 345-348.

15. Jingtian, X., Hailong, Z., Ye, T.T., 2011: Exploration of printing-friendly RFID antenna designs on paper substrates. In: 2011 IEEE International Conference on RFID, Pp 38-44.

16. Kavčič, U., Pivar, M., Dokič, M., Svetec, D.G., Pavlovič, L., Muck, T., 2014: UHF RFID tags with printed antennas on recycled papers and cardboards. Materials and Technology 48(2): 261-267.

17. Kasajová, M., Gigac, J., 2013: Comparison of print mottle and surface topography testing methods. Nordic Pulp \& Paper Research Journal 28(3): 443-449.

18. Kgwadi, M., Vourch, C.J., Harrison, D.J., Drysdale, T.D., 2014: On-demand printing of antennas for TV white-space communications. In: 2014 Loughborough Antennas and Propagation Conference (LAPC), Loughborough, UK., Pp 553-556. 
19. Kgwadi, M., Rizwan, M., Adhur Kutty, A., Virkki, J., Ukonen L., Drysdale, T.D., 2016: Performance comparison of inkjet and thermal transfer printed passive ultra-high-frequency radio-frequency identification tags. Antennas \& Propagation 10(14): 1507-1514.

20. Lakafosis, V, Rida, A., Vyas, R., Li, Y., Nikolaou, S., Tentzeris, M.M., 2010: Progress towards the first wireless sensor networks consisting of inkjet-printed. Paper-based RFIDenabled sensor tags. In: Proceedings of the IEEE 98(9): 1601-1609.

21. Merilampi, S., Ukkonen, L., Sydanheimo, L., Ruuskanen, P., Kivikoski, M., 2007: Analysis of silver ink bow-tie RFID tag antennas printed on paper substrates. International Journal of Antennas and Propagation, 9 pp.

22. Merilampi, S. L., Virkki, J., Ukkonen, L, Sydänheimo, L., 2014: Testing the effects of temperature and humidity on printed passive UHF RFID tags on paper substrate. International Journal of Electronics 101(5): 711-730.

23. Öhlund, T., Andersson, M., 2012: Effect of paper on electrical conductivity and pattern definition for silver nanoparticle inkjet ink. In: Proceedings LOPE-C, Pp 115-119.

24. Park, B.K., Kim, D., Jeong, S., Moon, J., Kim, J.S., 2007: Direct writing of copper conductive patterns by ink-jet printing. Thin Solid Films 515: 7706-7711.

25. Perelaer, J., de Gans, B.J., Schubert, U.S., 2006: Ink-jet printing and microwave sintering of conductive silver tracks. Advanced Materials 18(16): 2101-2104.

26. Rida, A., Li, Y., Vyas, R., Tentzeris, M.M., 2009: Conductive inkjet-printed antennas on flexible low-cost paper-based substrates for RFID and WSN applications. IEEE Antennas and Propagation Magazine 51(3): 13-23.

27. Taylor, D.H., Harrison, D., 2017: High volume digital printing of flexible electronics with continuous copper and aluminum. LOPEC 2017, Munich.

28. Tentzeris, M.M., Yang, L., Rida, A., Traille, A., Vyas, R., Wu, T., 2007: Inkjet-printed RFID tags on paper-based substrates for UHF "cognitive intelligence" applications. In: IEEE International Symposium on Personal, Indoor and Mobile Radio Communications. Athens, Greece, Pp 1-4.

29. Want, R., 2006: An inroduction to RFID technology. IEEE Pervasive Computing 5(1): 25-33.

30. Whyte, G., Harrison, D., Cumming, D., Drysdale, T., 2010: Direct printing of flexible metallic millimetre-wave frequency selective surfaces. In: 2010 IEEE Antennas and Propagation Society International Symposium (APSURSI), Toronto, Canada, Pp 1-4.

31. Yang, L., Rida, A., Vyas, R., Tentzeris, M.M., 2007: RFID tag and RF structures on a paper substrate using inkjet-printing technology. IEEE Transactions on Microwave Theory and Techniques 55(12): 2894-2900.

32. Xi, J., Zhu, H., Ye, T.T. 2011: Exploration of printing-friendly RFID antennas designs on paper substrates. In: 2011 IEEE International Conference, Pp 38-44.

33. Zichner, R., Baumann, R.R., 2011: Communication quality of printed UHF RFID transponder antennas. LOPEC, Messe Frankfurt, Germany, Pp 361-363. 
Juraj Gigac*, Mária Fišerová, Svetozár Hegyi

Pulp and Paper Research Institute

Dúbravská Cesta i 4

84I O4 Bratislava

Slovak Republic

*Corresponding author: gigac@vupc.sk 